\title{
Interleaved Boost-Flyback Converter with Boundary Conduction Mode for Power Factor Correction
}

\author{
Bor-Ren $\operatorname{Lin}^{\dagger}$ and Chih-Cheng Chien ${ }^{*}$ \\ ${ }^{\dagger *}$ Dept. of Electrical Eng., National Yunlin University of Science and Technology, Yunlin, Taiwan
}

\begin{abstract}
This paper presents a new interleaved pulse-width modulation (PWM) boost-flyback converter to achieve power factor correction (PFC) and regulate DC bus voltage. The adopted boost-flyback converter has a high voltage conversion ratio to overcome the limit of conventional boost or buck-boost converter with narrow turn-off period. The proposed converter has wide turn-off period compared with a conventional boost converter. Thus, the higher output voltage can be achieved in the proposed converter. The interleaved PWM can further reduce the input and output ripple currents such that the sizes of inductor and capacitor are reduced. Since boundary conduction mode (BCM) is adopted to achieve power factor correction, power switches are turned on at zero current switching (ZCS) and switching losses are reduced. The circuit configuration, principle operation, system analysis, and design consideration of the proposed converter are presented in detail. Finally, experiments conducted on a laboratory prototype rated at 500W were presented to verify the effectiveness of the converter.
\end{abstract}

Key words: Interleaved PWM, PFC, ZCS

\section{INTRODUCTION}

Recently high voltage step-up converters have been proposed for fuel-cell based DC converter [1]-[3], battery-discharged DC converter in UPS system [4]-[5], car auxiliary power supplies [6], automobile HID headlamps [7], [8], and medical equipment. The conventional boost converter cannot realize high voltage step-up due to the narrow allowed duty cycle. If the high duty cycle is used in the boost converter, the nonlinear voltage conversion characteristic due to the parasitic resistance is difficult to regulate output voltage. The conduction loss of power MOSFET also depends on the duty cycle. Cascade boost converters in [9]-[11] and the coupled-inductor converters in [12]-[16] have proposed for non-isolated circuit applications. Therefore, the drawback of the conventional boost converter can be overcome by these circuit topologies with high voltage step-up applications. In order to reduce the environmental power pollution and save energy waste, Environment Protection Agency (EPA) and Climate Saver Computing

Manuscript received Jan. 7, 2011; revised Jun. 13, 2012

Recommended for publication by Associate Editor Byung-Cho Choi.

${ }^{\dagger}$ Corresponding Author: linbr@yuntech.edu.tw

Tel: +886-5-5517456, Fax: +886-5-5312065, Nat'l Yunlin Univ. of Sci. and Tech.

*Dept. of Electrical Eng., National Yunlin University of Science and Technology, Taiwan
Initiative (CSCI) have been proposed to increase circuit efficiency for modern power supply units. Therefore, power factor correction (PFC) techniques [17]-[23] have been demanded for power converters with $P_{o} \geq 75 \mathrm{~W}$. Thus, the reactive power and line current harmonics are eliminated, and a sinusoidal line current is drawn from utility side.

This paper presents a new circuit topology to achieve high voltage step-up characteristic compared to the conventional boost converter and flyback converter. Since the adopted converter is operated in boundary conduction mode and interleaved pulse-width modulation (PWM), the input line current can be controlled to be a sinusoidal waveforms and the input ripple current can be partially cancelled each other. Therefore, input power factor can be controlled to be unity and total harmonic distortion of line current is reduced. The input inductance can also be reduced due to the interleaved PWM scheme. The boost and flyback converters with one MOSFET are connected in series at output side. The output voltage is the summation of these three voltages so that the converter has high output voltage. The advantages of the proposed converter are easy to be implemented with the commercial PWM IC such as UCC28061, high voltage step-up, less power switch count and wide duty cycle control. Experiments, taken from a laboratory prototype rated at $500 \mathrm{~W}$, are presented to demonstrate the circuit performance and verify the feasibility of the converter. 


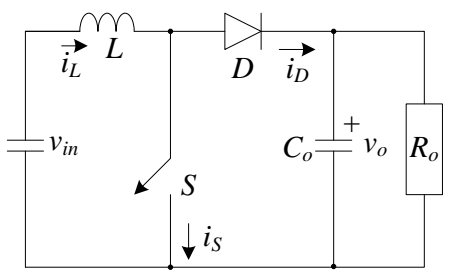

(a)

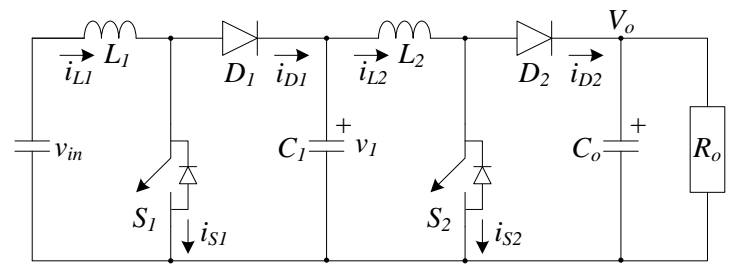

(b)

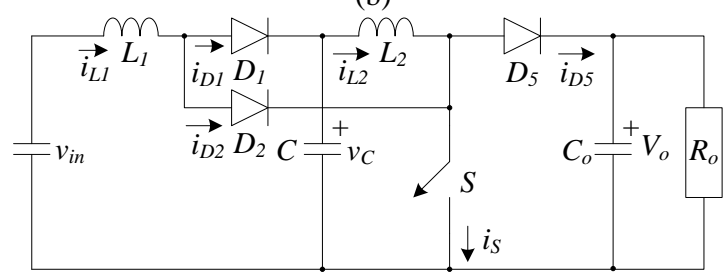

(c)

Fig. 1. Circuit configurations, (a) Traditional boost converter. (b) cascade boost converter. (c) Cascade boost converter with single switch.

\section{CIRCUIT CONFIGURATION}

Fig. 1(a) gives the circuit configuration of the conventional boost converter. The boost converter can step-up the input voltage $V_{o} / V_{i n}=1 /(1-\delta)$, where $\delta$ is the duty cycle of switch $S$. Generally the high step-up voltage gain is required in many emerging applications. But the boost converter should be operated at high duty cycle to achieve high voltage gain. Therefore, power is delivered to output load during a short period. This will result in low circuit efficiency. Fig. 1(b) gives the circuit configuration of the cascade boost converter. The voltage conversion ratio of the cascade boost converter is $V_{o} / V_{\text {in }}=1 /(1-\delta)^{2}$. The main disadvantages of the cascade boost converter are more circuit components and complex control scheme. In order to reduce power components and to simplify the control scheme, switches $S_{1}$ and $S_{2}$ in Fig. 1(b) can be reduced to only one switch as shown in Fig. 1(c). Therefore, the general PWM IC can be used to regulate the output voltage with high step-up gain. Fig. 2 shows the circuit configuration of the proposed converter with high step-up voltage conversion. There are two circuit modules in the proposed converter to achieve DC/DC power conversion, output voltage regulation and partially ripple current cancellation. In each module, the DC bus voltages of boost circuit, including $L_{1}, S_{1}, D_{1}$ and $C_{1}$, and flyback circuit, including $T_{1}, S_{1}, D_{2}$ and $C_{2}$, are connected in series to step-up output voltage. If the turns ratio of $T_{1}$ and $T_{2}$ is unity,

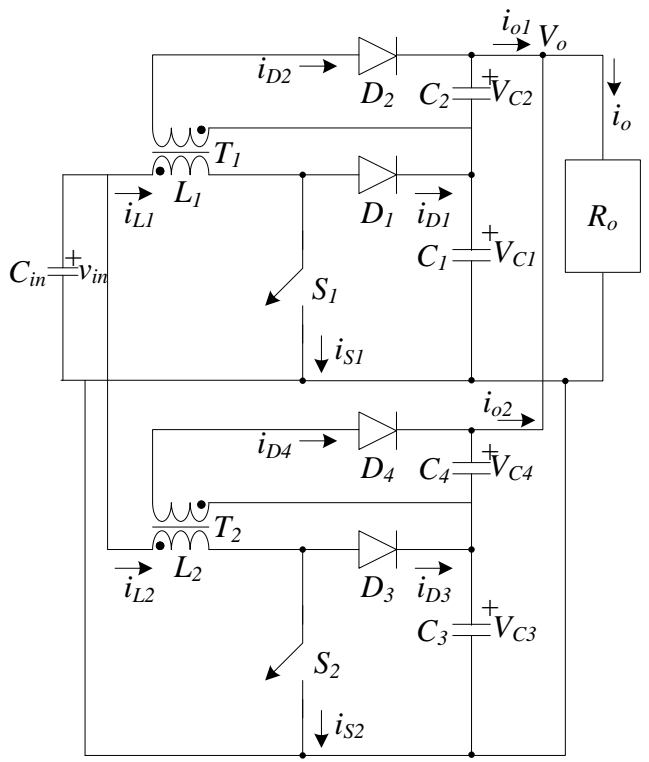

Fig. 2. Circuit configuration of the proposed converter.

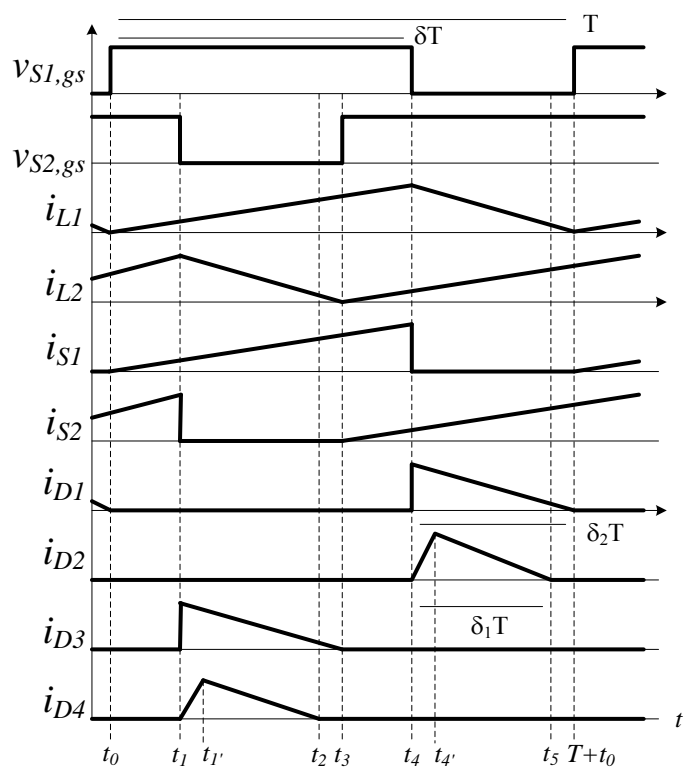

Fig. 3. Key waveforms of the proposed converter.

the total conversion ratio between DC bus voltage and input voltage is greater than or equal to $(1+\delta) /(1-\delta)$ with $D C M$ or CCM operation, respectively. This voltage conversion ratio is larger then the DC voltage conversion ratio of the conventional boost converter and flyback converter with unity turns ratio. Since the input inductor currents are interleaved by one-half of the switching period, the input ripple current is partially cancelled each other. Thus the input capacitance can be reduced.

\section{OPERATION PRINCIPLE}

In order to simplify the circuit analysis, some assumptions are made. Capacitances of $C_{1} \sim C_{4}$ are large enough such that 
voltages $V_{C 1} \sim V_{C 4}$ are constant. Magnetizing inductances of $T_{1}$ and $T_{2}$ are identical $L_{1}=L_{2}=L_{m}$. The turns ratio of $T_{1}$ and $T_{2}$ is $n=n_{p} / n_{s}$. All power semiconductors are ideal. The leakage inductances of $T_{1}$ and $T_{2}$ are identical. Based on the above assumptions, the proposed converter has six operation modes in a switching cycle. Fig. 3 shows the time sequence of key waveforms in the proposed converter. Before time $t_{0}$, $S_{1}$ is off and $S_{2}$ is on. Diode currents $i_{D 2} \sim i_{D 4}$ are all zero.

Mode $1\left[t_{0} \leq t<t_{1}\right]$ : At time $t_{0}$, switch $S_{1}$ is turned on. Thus diode $D_{1}$ is reverse biased. The voltage across inductor $L_{1}$ is equal to $v_{i n}$. Since both switches $S_{1}$ and $S_{2}$ are in the on-state. Inductor currents $i_{L 1}$ and $i_{L 2}$ increase with the slope rate of $V_{\text {in }} / L_{m}$. The secondary winding voltages of $T_{1}$ and $T_{2}$ are negative such that diodes $D_{2}$ and $D_{4}$ are reverse biased. Since diodes $D_{2}$ and $D_{4}$ are off, we can obtain $i_{L 1}=i_{L m 1}$ and $i_{L 2}=i_{L m 2}$. The switch currents $i_{S 1}=i_{L 1}$ and $i_{S 2}=i_{L 2}$. Output capacitors $C_{1} \sim C_{4}$ are discharged to supply load current. This mode ends at time $t_{1}$ when switch $S_{2}$ is turned off.

Mode $2\left[t_{1} \leq t<t_{2}\right]$ : At time $t_{1}$, switch $S_{2}$ is turned off. The energy stored in inductor $L_{2}$ is released to charge capacitances $C_{3}$ and $C_{4}$. Diodes $D_{3}$ and $D_{4}$ are conducting. The magnetizing inductance voltage $v_{L m 2}=-n V_{C 4}$. Thus, the magnetizing current $i_{L m 2}$ decreases as following.

$$
i_{L m 2}(t)=i_{L m 2}\left(t_{1}\right)-\frac{n V_{C 4}}{L_{m}}\left(t-t_{1}\right)
$$

where $n$ is the turns ratio between the primary winding and the secondary winding of $T_{1}$ and $T_{2}$. The inductor current $i_{L 2}$ also decreases.

$$
i_{L 2}(t)=i_{L 2}\left(t_{1}\right)+\frac{v_{i n}+n v_{C 4}-V_{C 3}}{L_{l k}}\left(t-t_{1}\right)
$$

Thus, the diode current $i_{D 4}$ is given as:

$$
i_{D 4}(t)=n\left[i_{L m 2}(t)-i_{L 2}(t)\right]
$$

In time interval $\left[t_{1} \leq t<t_{1},\right]$, diode current $i_{D 4}$ increases from zero ampere. After time $t_{1}$, the diode current $i_{D 4}$ decreases from its maximum value due to that $i_{L m 2}$ and $i_{L 2}$ are both decreasing. In converter cell 1 , the inductor current $i_{L 1}$ continuously increases in this mode. The time interval ends at time $t_{2}$ when diode current $i_{D 4}$ is decreased to zero. Then, diode $D_{4}$ is turned off at ZCS. There is no reverse recovery loss in diode $D_{4}$.

Mode $3\left[t_{2} \leq t<t_{3}\right]$ : At time $t_{2}$, diode $D_{4}$ is turned off at ZCS. Thus, the diode current $i_{D 3}$ is given as:

$$
i_{D 3}(t)=i_{D 3}\left(t_{2}\right)+\frac{v_{i n}-V_{C 3}}{L_{l k}+L_{m}}\left(t-t_{3}\right)
$$

Since $v_{i n}<V_{C 3}$, diode current $i_{D 3}$ continuously decreases in this mode. In converter cell 1 , the inductor current $i_{L 1}$ continuously increases in this mode. This mode ends at time $t_{3}$ when diode current $i_{D 3}$ is decreasing to zero. Then switch $S_{2}$ is turned on at this instant to achieve ZCS turn-on.

Mode $4\left[t_{3} \leq t<t_{4}\right]$ : This mode starts at time $t_{3}$ when diode current $i_{D 3}=0$ and $S_{2}$ is turned on. Thus, the circuit operation is the same as the circuit operation in mode 1 . Both inductor currents $i_{L 1}$ and $i_{L 2}$ increase in this mode and diodes $D_{1} \sim D_{4}$ are all reverse biased. This mode ends at time $t_{4}$ when switch $S_{1}$ is turned off.

Mode $5\left[t_{4} \leq t<t_{5}\right]$ : At time $t_{4}$, switch $S_{1}$ is turned off. The energy stored in inductor $L_{1}$ is released to charge capacitances $C_{1}$ and $C_{2}$. Diodes $D_{1}$ and $D_{2}$ are conducting. The magnetizing voltage $v_{L m 1}=-n V_{C 2}$. Thus, the magnetizing current $i_{L m 1}$ decreases as following.

$$
i_{L m 1}(t)=i_{L m 1}\left(t_{4}\right)-\frac{n V_{C 2}}{L_{m}}\left(t-t_{4}\right)
$$

The inductor current $i_{L 1}$ also decreases.

$$
i_{L 1}(t)=i_{L 1}\left(t_{4}\right)+\frac{v_{i n}+n v_{C 2}-V_{C 1}}{L_{l k}}\left(t-t_{4}\right)
$$

The diode current $i_{D 2}$ is given as:

$$
i_{D 2}(t)=n\left[i_{L m 1}(t)-i_{L 1}(t)\right]
$$

In time interval $\left[t_{4} \leq t<t_{4}\right.$, $]$, diode current $i_{D 2}$ increases from zero ampere. After time $t_{4}$, the diode current $i_{D 2}$ decreases from its maximum value due to that $i_{L m 1}$ and $i_{L 1}$ are both decreasing. In converter cell 2 , the inductor current $i_{L 2}$ increases in this mode. At time $t_{5}$, diode current $i_{D 2}$ is decreased to zero. Then diode $D_{2}$ is turned off at ZCS. There is no reverse recovery loss in diode $D_{2}$.

Mode $6\left[t_{5} \leq t<T+t_{0}\right]$ : This mode starts at time $t_{5}$ when diode current $i_{D 2}=0$. Then diode $D_{2}$ is off at ZCS. The diode current $i_{D 1}$ is given as:

$$
i_{D 1}(t)=i_{D 1}\left(t_{5}\right)+\frac{v_{i n}-V_{C 1}}{L_{l k}+L_{m}}\left(t-t_{5}\right)
$$

Since $v_{i n}<V_{C 1}$, diode current $i_{D 1}$ is decreasing in this mode. The inductor current $i_{L 2}$ continuously increases in this mode. At time $T+t_{0}$, diode current $i_{D 1}$ is decreased to zero. Then switch $S_{1}$ is turned on at this instant to achieve ZCS turn-on. Then, the operation mode in this switching cycle is completed and the circuit goes to the next switching operation.

\section{STEADy STATE ANALYSIS}

In steady state analysis, transformers $T_{1}$ and $T_{2}$ are modeled as the magnetizing inductors $L_{1}$ and $L_{2}$ and leakage inductors $L_{l k}$. Based on the voltage-second balance on the primary sides of $T_{1}$ and $T_{2}$, we can derive the average voltages $V_{C 1}$ and $V_{C 3}$.

$$
V_{C 1}=V_{C 3}=\frac{v_{i n}}{1-\delta}
$$

where $\delta$ is the duty cycle of switches $S_{1}$ and $S_{2}$. In the same manner, the average voltages $V_{C 2}$ and $V_{C 4}$ can be obtained due to the voltage-second balance on the secondary sides of $T_{1}$ and $T_{2}$.

$$
V_{C 2}=V_{C 4}=\frac{k\left[v_{i n}\left(1-\delta_{1}\right)-V_{C 1}\left(1-\delta-\delta_{1}\right)\right]}{n \delta_{2}(1+k)}
$$

where $k=L_{m} / L_{l k},\left(\delta_{1} T\right)$ is the turn-on time of diodes $D_{2}$ and $D_{4}$ and $\left(\delta_{2} T\right)$ is the turn-on time of diodes $D_{1}$ and $D_{3}$. 


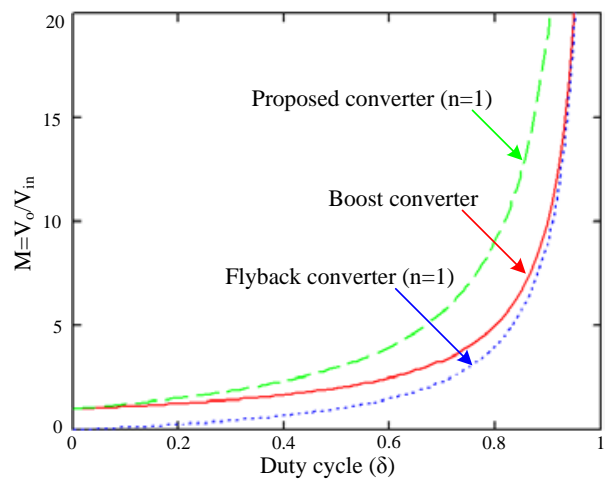

Fig. 4. Comparisons of the voltage conversion ratios of the proposed converter, boost converter and flyback converter with unity turns ratio.

Thus the DC voltage conversion ratio of the proposed converter is derived as:

$$
\begin{aligned}
M & =\frac{V_{o}}{v_{\text {in }}}=\frac{V_{C 1}+V_{C 2}}{v_{\text {in }}} \\
& =\frac{1}{1-\delta}+\frac{k\left[\left(1-\delta_{1}\right)-V_{C 1}\left(1-\delta-\delta_{1}\right) / v_{\text {in }}\right]}{n \delta_{1}(1+k)}
\end{aligned}
$$

If we assumed that the leakage inductance is neglected and the turn-on time is $\delta_{1} T=T-\delta T$, then the DC voltage conversion ratio in (11) can be further expressed as:

$$
M=\frac{V_{o}}{v_{i n}}=\frac{1}{1-\delta}+\frac{\delta}{n(1-\delta)}=\frac{n+\delta}{n(1-\delta)}
$$

Fig. 4 shows the theoretical voltage conversion ratio of boost converter, flyback converter and the proposed converter. It is clear that the proposed converter has higher voltage step-up gain. In time interval $\left[t_{0}-t_{4}\right], S_{1}$ is in the on-state. The following equations can be derived:

$$
i_{L 1}\left(t_{4}\right)==i_{L m 1}\left(t_{4}\right)=\frac{v_{i n} \delta T}{L_{m}+L_{l k}}
$$

In mode $5\left[t_{4}-t_{5}\right], D_{1}$ and $D_{2}$ are conducting. Thus, the leakage inductor voltage can be derived as:

$$
v_{L k}=v_{\text {in }}+n V_{C 2}-V_{C 1}<0
$$

The inductor current $i_{L 1}$ in mode 5 is given as:

$$
\begin{aligned}
i_{L 1}(t) & =i_{L 1}\left(t_{4}\right)+\frac{v_{i n}+n V_{C 2}-V_{C 1}}{L_{l k}}\left(t-t_{4}\right) \\
& =\frac{v_{i n} \delta T}{L_{m}+L_{l k}}+\frac{v_{i n}+n V_{C 2}-V_{C 1}}{L_{l k}}\left(t-t_{4}\right)
\end{aligned}
$$

The magnetizing current of $T_{1}$ in mode 5 is given as:

$$
\begin{aligned}
i_{L m 1}(t) & =i_{L m 1}\left(t_{4}\right)-\frac{n V_{C 2}}{L_{m}}\left(t-t_{4}\right) \\
& =\frac{v_{i n} \delta T}{L_{m}+L_{l k}}-\frac{n V_{C 2}}{L_{m}}\left(t-t_{4}\right)
\end{aligned}
$$

The diode current $i_{D 2}$ is expressed as:

$$
i_{D 2}(t)=n\left[i_{L m 1}(t)-i_{L 1}(t)\right]
$$

The voltage stresses of diodes are given as:

$$
v_{D 1, \text { stress }}=v_{D 3, \text { stress }}=V_{C 1}=\frac{v_{\text {in }}}{1-\delta}
$$

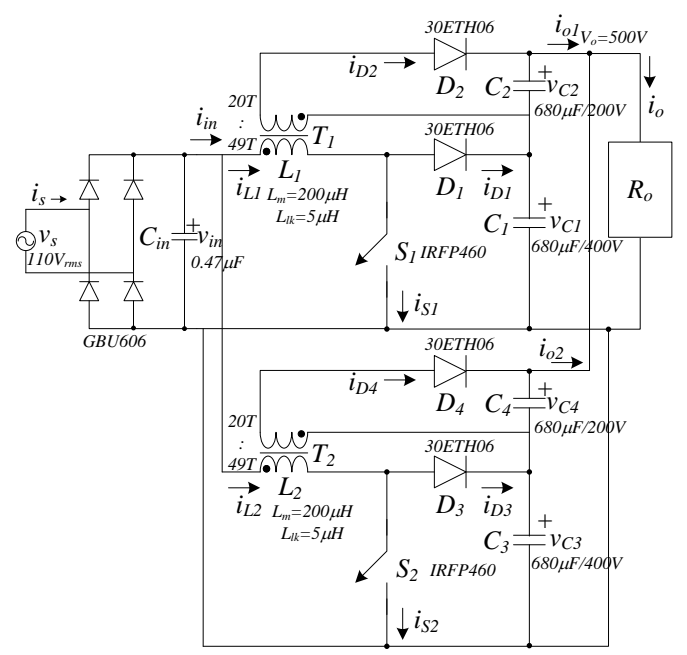

Fig. 5. Circuit configuration and specifications of the prototype circuit.

$$
v_{D 2, \text { stress }}=v_{D 4, \text { stress }}=v_{\text {in }} / n+V_{C 2}
$$

The voltage stress of switches $S_{1}$ and $S_{2}$ is given as:

$$
v_{S 1, \text { stress }}=v_{S 2, \text { stress }}=\frac{v_{\text {in }}}{1-\delta}
$$

\section{EXPERIMENTAL RESULTS}

The proposed converter with BCM operation for high step-up voltage conversion was built and tested to achieve unity power factor, line current harmonics reduction and partially ripple current cancellation at input and output sides. Experimental results based on a laboratory 500W prototype are provided to verify the effectiveness of the proposed converter. Fig. 5 gives the circuit configuration of the prototype circuit. An interleaved BCM mode control IC UCC28061 is adopted to generate two PWM signals and regulate output voltage. The design procedure of the boost PFC with BCM scheme can be found in the application notes from Texas Instruments website. Since the adopted converter is operated at BCM mode, an input capacitor $C_{\text {in }}$ is added after the diode rectifier to filter high frequency harmonic current. Fig. 6 shows the measured line voltage $v_{s}$ and line current $i_{s}$ at $30 \%$ and $100 \%$ load conditions. It is clear that line current is a sinusoidal waveform. The measured power factor is 0.98 and total harmonic distortion of line current is $18.9 \%$. Fig. 7 gives the measured results of $v_{S 1, g s}, i_{i n}, i_{L 1}$ and $i_{L 2}$ at $30 \%$ and $100 \%$ load conditions. The input current $i_{\text {in }}$ has twice switching frequency compared to the frequency of $i_{L 1}$ and $i_{L 2}$. Thus, the boost inductances $L_{1}$ and $L_{2}$ can be reduced. Fig. 8 gives the measured results of $v_{S 1, g s}, v_{S 2, g s}, i_{S 1}$ and $i_{S 2}$ at $30 \%$ and $100 \%$ load conditions. Fig. 9 shows the measured results of $v_{S 1, g s}, v_{S 2, g s}, i_{D 1}$ and $i_{D 3}$ at $30 \%$ and $100 \%$ load conditions. Fig. 10 gives the measured waveforms of $v_{S 1, g s}, v_{S 2, g s}, i_{D 2}$ and $i_{D 4}$ at $30 \%$ and $100 \%$ load conditions. From Figs. 7-10, we can see that the inductor currents and diode currents are interleaved each other. Thus input and output ripple currents are reduced such that the input and 
output capacitances can be reduced. Since BCM operation is adopted in the proposed converter, all diodes are turned off at ZCS. Thus, there is no reverse recovery loss on each diode. Two power switches are turned on at ZVS. The measured circuit efficiencies of the proposed converter are shown in Fig. 11. The proposed converter has better circuit efficiency compared with the conventional interleaved boost converter with BCM scheme.

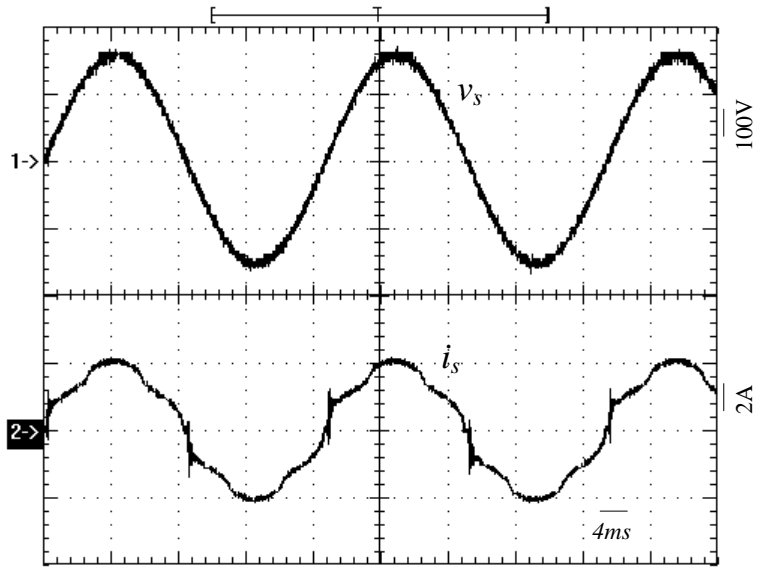

(a)

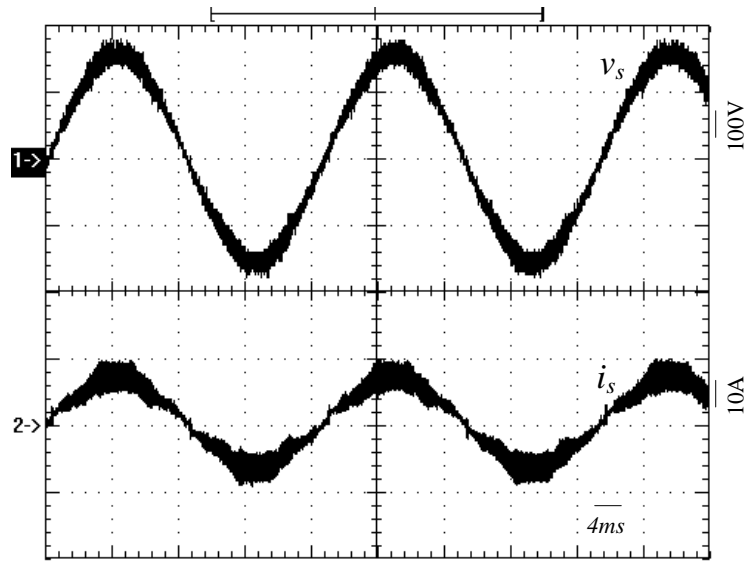

(b)

Fig. 6. Measured line voltage $v_{s}$ and line current $i_{s}$ at (a) $30 \%$ load (b) full load.

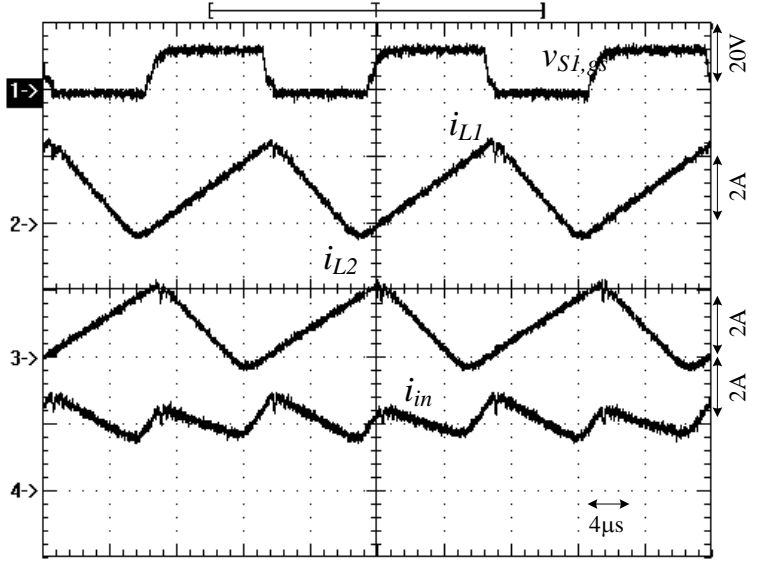

(a)

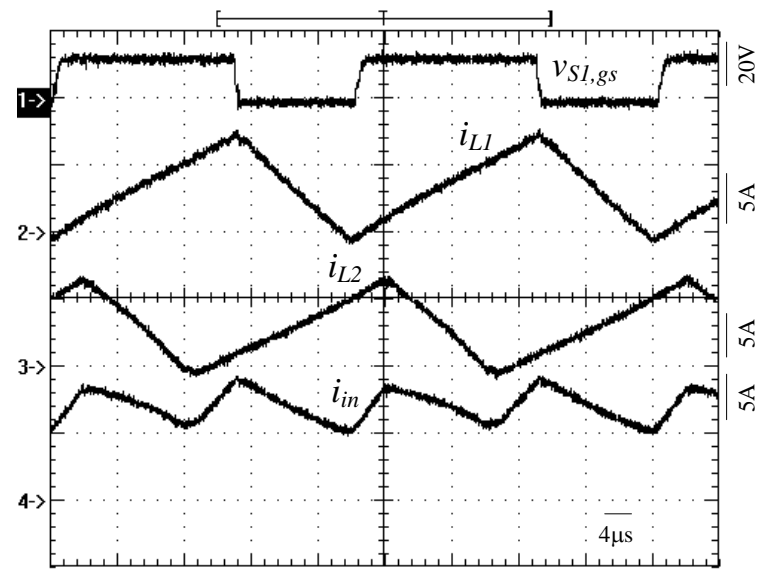

(b)

Fig. 7. Measured results of $v_{S 1, g s}, i_{i n}, i_{L 1}$ and $i_{L 2}$ at (a) $30 \%$ load (b) full load.

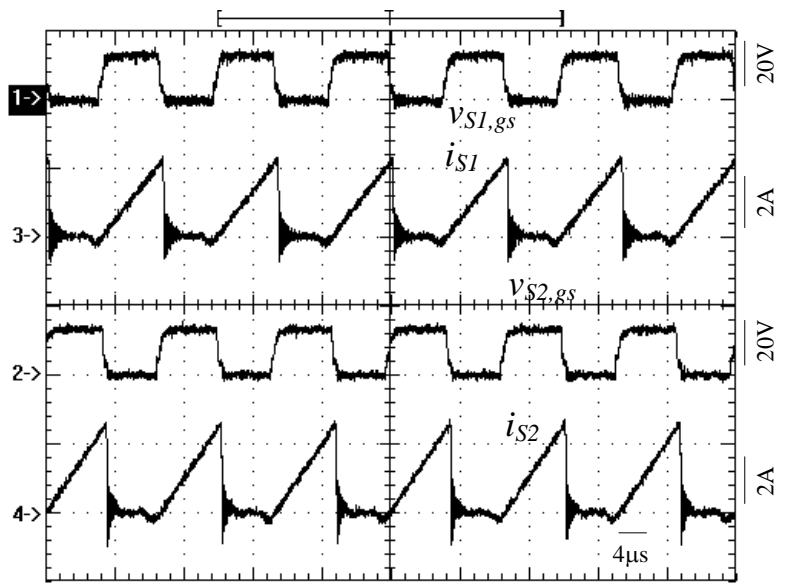

(a)

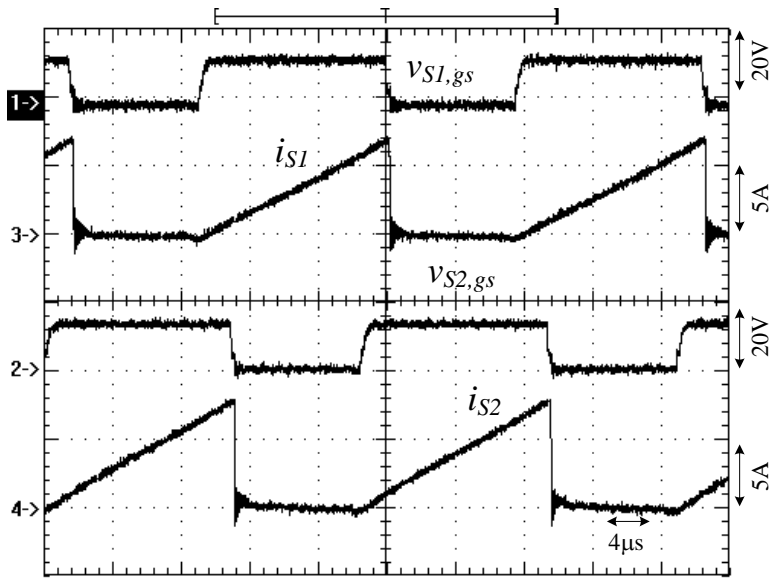

(b)

Fig. 8. Measured results of $v_{S 1, g s}, v_{S 2, g s}, i_{S 1}$ and $i_{S 2}$ at (a) $30 \%$ load (b) full load. 


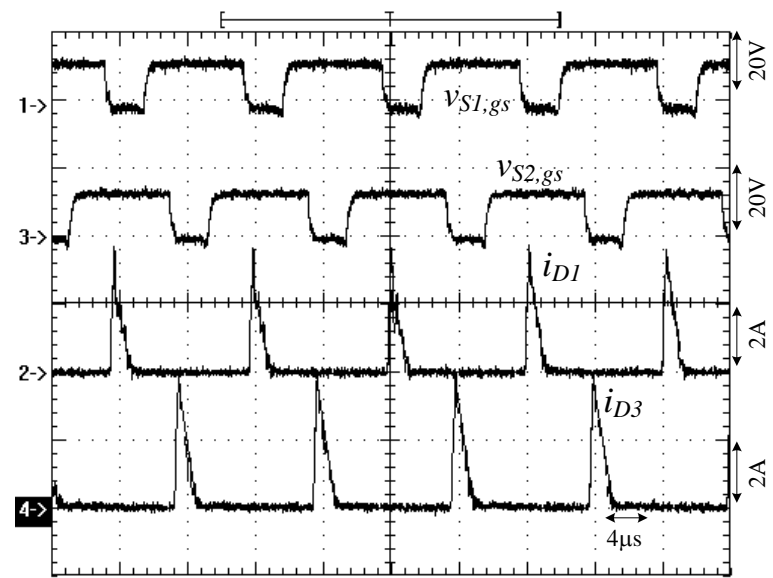

(a)

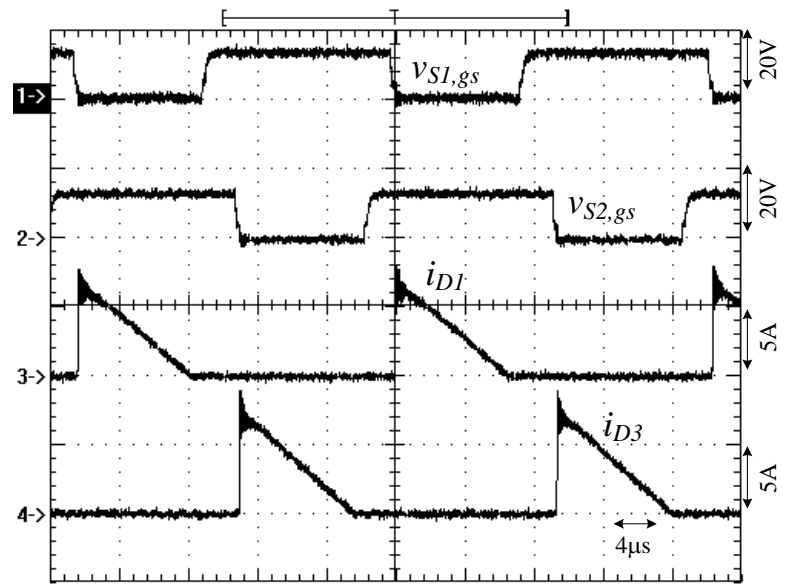

(b)

Fig. 9. Measured results of $v_{S 1, g s}, v_{S 2, g s}, i_{D 1}$ and $i_{D 3}$ at (a) $30 \%$ load (b) full load.

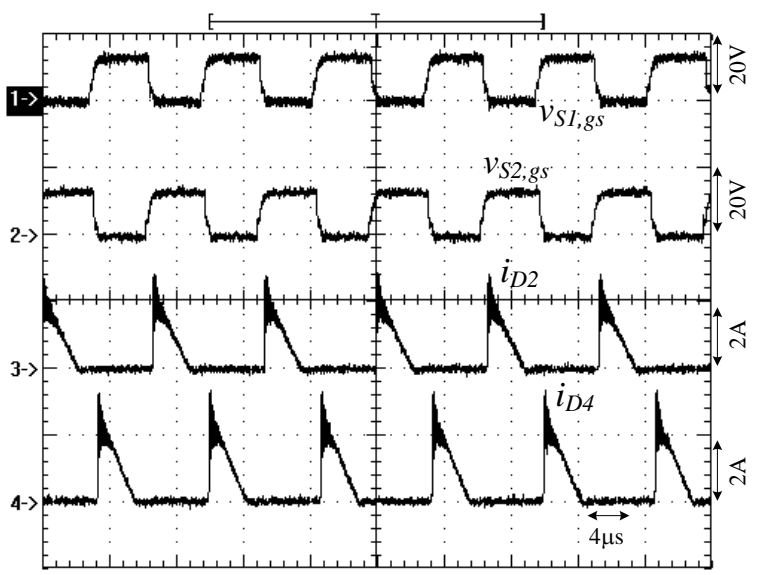

(a)

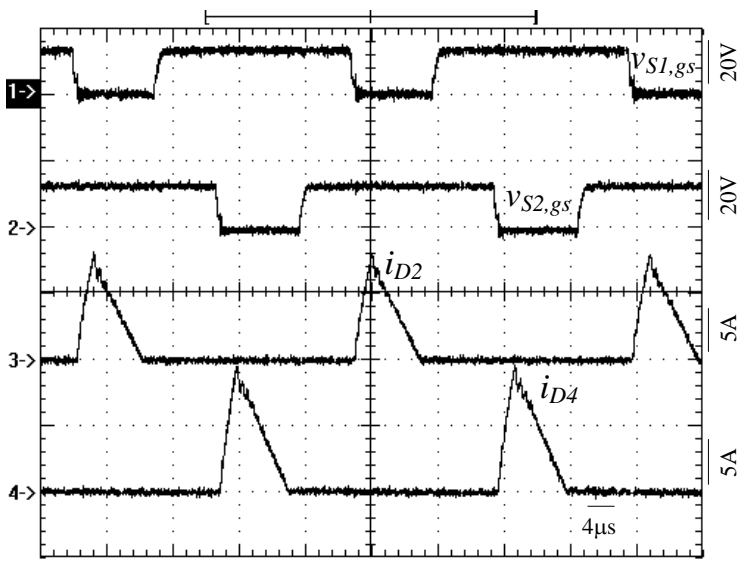

(b)

Fig. 10. Measured results of $v_{S 1, g s}, v_{S 2, g s}, i_{D 2}$ and $i_{D 4}$ at (a) $30 \%$ load (b) full load.

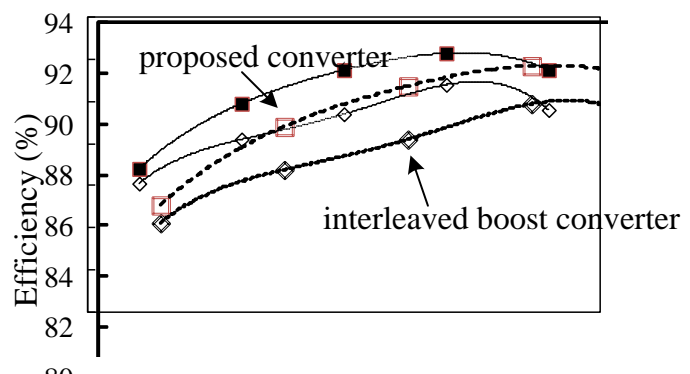

$\mathrm{P}_{\mathrm{o}}(\mathrm{W})$

Fig. 11/ Measured circuit efficiencies of the proposed converter and interleaved boost converter with BCM operation.

\section{CONCLUSION}

An interleaved boost-flyback converter operated in BCM mode is presented to achieve nearly unity power factor, low total harmonic distortion and high voltage step-up features. All diodes are turned off at ZCS and switches are turned on at ZCS. There is no reverse recovery loss on the rectifier diodes and the low cost fast recovery diodes can be used in the adopted circuit. The adopted converter can be used in fuel cell system, PV cell system, battery discharge system for DC-AC converter with high voltage step-up function. The adopted converter can also be used for high output voltage application with utility mains input and high input power factor demanded. The circuit configuration, operation principle and steady state analysis are demonstrated as well. Finally the performance of the proposed converter is verified from the experiments based on a laboratory prototype.

\section{ACKNOWLEDGMENT}

This paper is supported by the National Science Council of Taiwan under Grant NSC 99-2221-E-224-083-MY2. 


\section{REFERENCES}

[1] J. M. Correa, F. A. Farret, M. G. Simoes, and V. A. Popov, "Sensitivity analysis of the modeling parameters used in simulation of proton exchange membrane fuel cells," IEEE Trans. Energy Convers., Vol. 20, Vol. 1, pp. 211-218, Mar. 2005.

[2] J. L. Duarte, M. Hendrix and M. G. Simoes, "Three-port bidirectional converter for hybrid fuel cell systems," IEEE Trans. Power Electron., Vol. 22, No. 2, pp. 480-487, Mar. 2007.

[3] F. Z. Peng, H. Li, G. J. Su and J. S. Lawler, “A new ZVS bidirectional DC-DC converter for fuel cell and battery application,” IEEE Trans. Power Electron., Vol. 19, No. 1, pp. 54-65, Jan. 2004.

[4] Q. Zhao, F. Tao, and F. C. Lee, "A front-end dc/dc converter for network server applications," in Proc. of IEEE PESC Conference, pp. 1535-1539, 2001.

[5] I. Baibi and R. Gules, "Isolated dc-dc converters with high-output voltage for TWTA telecommunication satellite applications,” IEEE Trans. Power Electron., Vol. 18, No. 3, pp. 975-984, Jul. 2003.

[6] F. L. Luo, "Re-lift circuits: a new dc-dc step-up boost converter," IEE Proceedings - Electronics Letters, Vol. 33, No. 1, pp. 5-7, 1997.

[7] Q. Zhao, F. Tao, Y. Hu, and F. C. Lee, “Active-clamp dc/dc converters using magnetic switches," in Proc. of IEEE APEC Conf., pp. 946-952, 2001.

[8] A. Reatti, "Low-cost high power-density electronic ballast for automotive HID lamp,” IEEE Trans. Power Electron., Vol. 15, No. 2, pp. 361-368, Mar. 2000.

[9] C. M. Wildrick, F. C. Lee, B. H. Cho, and B. Choi, “A method of defining the load impedance specification for a stable distributed power system," IEEE Trans. Power Electron., Vol. 10, No. 3, pp. 280-285, May 1995.

[10] X. G. Feng, J. J. Liu, and F. C. Lee, "Impedance specifications for stable dc distributed power systems," IEEE Trans. Power Electron., Vol. 17, No. 2, pp. 157-162, Mar. 2002.

[11] L. Huber and M. M. Jovanovic, “A design approach for serere power supplies for networking," in Proc. of IEEE APEC Conf., pp. 1163-1169, 2000.

[12] Q. Hu and Z. Lu, "A novel step-up VRM two-phase interleaved coupled-boost converter," in Proc. of IEEE PESC Conf., pp. 1-5, 2006.

[13] R. J. Wai and R. Y. Duan, "High-efficiency DC/DC converter with high voltage gain," IEE Proc. - Electric Power Applications, Vol. 152, No. 4, pp. 793-802, 2005.

[14] S. Senini and P. J. Wolfs, "The coupled inductor filter: analysis and design for AC systems," IEEE Trans. Ind. Electron., Vol. 45, No. 4, pp. 574-578, Aug. 1998.

[15] M. Xu, J. Zhou, K. Yao, and F. C. Lee, "Small signal modeling of a high bandwidth voltage regulator using coupled inductors,” IEEE Trans. Power Electron., Vol. 22, No. 2, pp. 399-406, Mar. 2007.

[16] W. Li and X. He, "ZVT interleaved boost converters for high-efficiency, high step-up DC-DC conversion,” IET Proc. - Electric Power Applications, Vol. 1, No. 2, pp. 284-290, 2007.

[17] X.-S. Pu, T.-H. Nguyen, D.-C. Lee, and S.-G. Lee, "Identification of DC-link capacitance for single-phase
AC/DC PWM converters," Journal of Power Electronics, Vol. 10, No.3, pp.270-276, May 2010.

[18] K.-T. Kim, W.-Y. Choi, J.-M. Kwon, and B.-H. Kwon, “A single-stage AC/DC converter with low voltage stresses and reduced switching losses," Journal of Power Electronics, Vol. 9, No. 6, pp.823-834, Nov. 2009.

[19] M. Jabbari and H. Farzanehfard, "A new soft switching step-down/up converter with inherent PFC performance," Journal of Power Electronics, Vol. 9, No. 6, pp. 835-844, Nov. 2009.

[20] Y.-C. Kim, L. Jin, J.-M. Lee, and J. Choi, "Direct digital control of single-phase AC/DC PWM converter system," Journal of Power Electronics, Vol. 10, No. 5, pp. 518-527, Sep. 2010.

[21] J. J. Lee, J. M. Kwon, E. H. Kim, W. Y. Choi and B. H. Kwon, "Single-stage single-switch PFC flyback converter using a synchronous rectifier," IEEE Trans. Ind. Electron., Vol. 55, No. 3, pp. 1352-1365, Mar. 2008.

[22] Y. M. Liu and L. K. Chang, "Single-stage soft-switching AC-DC converter with input-current shaping for universal line applications,” IEEE Trans. Ind. Electron., Vol. 56, No. 2, pp. 467-478, Feb. 2000.

[23] O. Carcia, J. A. Cobos, R. Prieto, P. Alou, and J. Uceda, "Single phase power factor correction: A survey," IEEE Trans. Power Electron., Vol. 18, No. 3, pp. 749-755, May 2003.

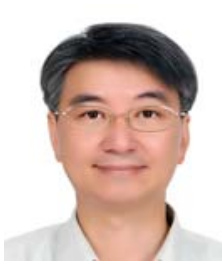

Bor-Ren Lin received his B.S. in Electronic Engineering from the National Taiwan University of Science and Technology, Taipei, Taiwan, in 1988, and his M.S. and Ph.D. in Electrical Engineering from the University of Missouri, USA, in 1990 and 1993, respectively. From 1991 to 1993 , he was a Research Assistant with the Power Electronic Research Center, University of Missouri. Since 1993, he has been with the Department of Electrical Engineering, National Yunlin University of Science and Technology, Douliou, Taiwan, where he is currently a Professor. He has authored more than 200 published technical journal papers in the area of power electronics. His main research interests include power-factor correction, multilevel converters, active power filters, and soft-switching converters. Dr. Lin is an Associate Editor of the IEEE Transactions on Industrial Electronics, The Institution of Engineering and Technology Proceedings-Power Electronics and the Journal of Power Electronics. He was the recipient of Research Excellence Awards in 2004, 2005, 2007 and 2011 from the College of Engineering, National Yunlin University of Science and Technology. He received best paper awards from the IEEE Conference on Industrial Electronics and Applications 2007 and 2011, from the Taiwan Power Electronics 2007 Conference, and from the IEEE Power Electronics and Drive Systems 2009 Conference.

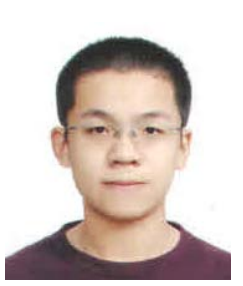

Chih-Cheng Chien is currently working toward his M.S. in Electrical Engineering from the National Yunlin University of Science and Technology, Yunlin, Taiwan, ROC. His research interests include the design and analysis of power factor correction techniques, switching mode power supplies and soft switching

converters. 